\title{
Proinsulin C-peptide: Friend or foe in the development of diabetes-associated complications?
}

\author{
Lina Nordquist' \\ $M$ Johansson ${ }^{2}$ \\ 'Department of Medical Cell Biology, \\ Division of Integrative Physiology, \\ Uppsala University, Uppsala, Sweden; \\ ${ }^{2}$ Department of Pathology, University \\ of California, San Francisco, San \\ Francisco, USA
}

\begin{abstract}
The proinsulin connecting peptide, C-peptide, is a cleavage product of insulin synthesis that is co-secreted with insulin by pancreatic $\beta$-cells following glucose stimulation. Recombinant insulin, used in the treatment of diabetes, lacks C-peptide and preclinical and clinical studies suggest that lack of C-peptide may exacerbate diabetes-associated complications. In accordance with this, several studies suggest that $\mathrm{C}$-peptide has beneficial effects in a number of diabetes-associated complications. C-peptide has been shown to prevent diabetic neuropathy by improving endoneural blood flow, preventing neuronal apoptosis and by preventing axonal swelling. In the vascular system, C-peptide has been shown to prevent vascular dysfunction in diabetic rats, and to possess anti-proliferative effects on vascular smooth muscle cells, which may prevent atherosclerosis. However, C-peptide depositions have been found in arteriosclerotic lesions of patients with hyperinsulinemic diabetes and C-peptide has been shown to induce pro-inflammatory mediators, such as nuclear factor kappa B, inducible nitric oxide synthase, and cyclooxygenase-2, indicating that $\mathrm{C}$-peptide treatment could be associated with side-effects that may accelerate the development of diabetes-associated complications. This review provides a brief summary of recent research in the field and discusses potential beneficial and detrimental effects of C-peptide supplementation.
\end{abstract}

Keywords: C-peptide, proinsulin, diabetes, cardiovascular

\section{Introduction}

The vascular endothelium is pivotal in all aspects of cardiovascular physiology and pathology. It is well known that patients with diabetes mellitus are subject to an increased risk of developing atherosclerosis, which is the principal cause of heart attack, stroke, and gangrene of the extremities. Diabetes accelerates atherosclerosis (Brownlee 2001), microangiopathy and abnormalities in small vessel function, complications that significantly contribute to diabetes-induced morbidity (Jensen et al 1989). Aggressive treatment of hyperglycemia has been shown to be associated with a decrease in diabetes-associated complications, but is not sufficient to fully normalize the incidence of cardiovascular disease in patients with diabetes (DCCT 1993). This clinical observation suggests that there may be other factors that causally contribute to the development of diabetes complications.

During insulin biosynthesis, the hormone is synthesized as a single polypeptide, proinsulin, which is subsequently proteolytically processed into insulin inside insulin granules. The mature hormone consists of two polypeptides, the so called A- and B-chain, while the connecting peptide is detached and released into the circulation. This proinsulin-connecting peptide, ie, C-peptide, is thus a product of insulin synthesis, and is released together with the mature hormone during hyperglycemia. Thus, when insulin synthesis is impaired, patients will also become C-peptide-deficient. 
However, recombinant insulin does not contain the C-peptide and recent research indicates that this peptide may play an important physiological role. The current knowledge regarding the effects of $\mathrm{C}$-peptide on proliferation, immune response, and cell growth will be reviewed briefly.

\section{Beneficial effects of C-peptide}

Exogenous C-peptide administration has beneficial effects in many tissues commonly affected by diabetic complications, a finding supported by the fact that pancreas transplantation reduces diabetic lesions after ten years of normoglycemia, when compared to treatment with recombinant insulin (Fioretto et al 1998; Fiorina et al 2003). Diabetes-induced cardiovascular complications, such as decreased blood flow in the extremities, have been shown to be prevented by C-peptide (Johansson et al 1992, 2003; Forst et al 1998b; Hansen et al 2002). In addition, C-peptide improves diabetes-induced erythrocyte deformability, which in turn likely improves oxygen availability and uptake in affected tissues (Johansson et al 1992; De la Tour et al 1998; Kunt et al 2000). Furthermore, C-peptide prevents diabetic neuropathy via improvements of endoneural blood flow and by preventing axonal swelling (Johansson et al 2000; Sima et al 2004). In the kidneys, C-peptide prevents renal damage by reducing glomerular hyperfiltration, hypertrophy, and proteinuria (Forst et al 1998a; Sjoquist et al 1998; Johansson et al 2000; Samnegard et al 2001, 2004; Huang et al 2002; Nordquist et al 2007; Stridh et al 2008). Several studies report a reduction of microvascular complications in patients with type 1 , as well as type 2 , diabetes with circulating concentrations of C-peptide close to physiological levels (Fiorina et al 2003; Manzella et al 2003; Steffes et al 2003; Sari and Balci 2005; Shapiro et al 2006). Pancreatic transplantation, which restores not only insulin secretion, but also that of C-peptide, is associated with prevention and even reversal of diabetic complications (Lee et al 2006). Despite this, recent research indicates that $\mathrm{C}$-peptide may not be beneficial under all circumstances.

Type 2 diabetes is a disease associated with endothelial dysfunction and the development of insulin resistance. Type 2 diabetes progresses through two stages. In the first stage, tissue insulin action decreases, resulting in increased insulin and C-peptide production. The second stage is reached when "pancreatic exhaustion" causes insulin and C-peptide production to cease. Thus, during disease progression, patients exhibit high circulating concentrations of C-peptide. Atherosclerosis is an inflammatory process, and in addition to hemodynamic and metabolic factors, inflammation appears to be a potential pathogenic mechanism in the development of the disease (Navarro et al 2003). Although it has not been elucidated whether type 2 diabetics suffer from inflammation to a greater extent than type 1 diabetic patients, plasma levels of interleukin-6 (IL-6) appear to be associated with C-peptide concentrations in type 2 diabetic patients (Heliövaara et al 2005). Interestingly, C-peptide depositions have been found in arteriosclerotic lesions of patients with diabetes (Marx et al 2004).

\section{Effects of C-peptide on cell proliferation and apoptosis}

Atherosclerosis is characterized by features of chronic inflammation and proliferative processes. In the development of atherosclerosis, pathological proliferation and migration of vascular smooth muscle cells are critically involved in the formation of atherosclerotic plaques. C-peptide has been shown to prevent vascular dysfunction in diabetic rats (Ido et al 1997), and to possess antiproliferative effects on vascular smooth muscle cells (Kobayashi et al 2005), which indicates that treatment with $\mathrm{C}$-peptide may delay disease progression in atherosclerosis. The administration of C-peptide (1 to $100 \mathrm{nM}$ ) appears to suppress hyperglycemiainduced hyperproliferation of aortic smooth muscle cells (Kobayashi et al 2005). The antiproliferative effects of $\mathrm{C}$-peptide on vascular smooth muscle cells are mediated through the inhibited expression of the platelet-derived growth factor- $\beta$ (PDGF- $\beta$ ) receptor and increased phosphorylation of mitogen-activated protein kinase (MAPK) (Kobayashi et al 2005). This stimulating effect on MAPK has been described also for other cell types and experimental settings (Kitamura et al 2001; Zhong et al 2004, 2005). Paradoxically, in other studies, C-peptide has been reported to act as a mitogen by the induction of vascular smooth muscle cell proliferation (Walcher et al 2006), a finding suggesting proatherogenic activities of the peptide. Whether these effects occur in vivo remains to be determined.

Atherosclerotic lesions originate from inflammatory and proliferative responses elicited by injuries to the endothelium and smooth muscle of arterial walls. A large number of growth factors, as well as cytokines, chemokines, and vasoregulators, interact to initiate and propagate the disease. The transcription factor nuclear factor kappa $B(N F-\kappa B)$ is of particular interest and plays a pivotal role in the early stages of disease progression. NF- $\kappa \mathrm{B}$ orchestrates transcription of genes encoding various cell-adhesion molecules, as well as inducible nitric oxide synthase (iNOS). NF- $\kappa B$ can be activated by inflammatory and proliferative stimuli 
(Witztum and Steinberg 1991), and activated NF- $\kappa B$ is found in vascular smooth muscle cells, endothelial cells, and macrophages in atherosclerotic lesions of human patients (Brand et al 1996). It has been postulated that NF- $\kappa B$ promotes chronic inflammation and may accelerate diabetic vascular disease. In this context, it is of importance that $\mathrm{NF}-\kappa \mathrm{B}$ activity is increased during hyperglycemia (Pieper and Riaz-ul-Haq 1997; Yerneni et al 1999). The inhibition of protein kinase $\mathrm{C}(\mathrm{PKC})$, an upstream regulator of $\mathrm{NF}-\kappa \mathrm{B}$ activity, has been shown to inhibit hyperglycemia-induced $\mathrm{NF}-\kappa \mathrm{B}$ activation in vascular smooth muscle cells and aortic endothelial cells (Pieper and Riaz-ul-Haq 1997; Yerneni et al 1999). In Swiss 3 T3 fibroblasts, C-peptide (1 nM) has been shown to stimulate the $\mathrm{PKC} / \mathrm{NF}-\kappa \mathrm{B}$ signaling pathway (Kitazawa et al 2006).

During disease progression in type II diabetes there is typically an increase in circulating concentrations of $\mathrm{C}$-peptide. This correlation may indicate that C-peptide has negative effects on diabetes-associated complications. Alternatively, it is possible to argue that C-peptide is indeed renoprotective, and that disease progression would be further accelerated in the absence of the peptide. Notably, diabetesassociated complications normally develop slower in patients with type I diabetes, where patients have a relative lack of C-peptide, as compared to patients with type II diabetes, where patients typically have increased circulating C-peptide. However, potential mechanisms for this discrepancy have not been thoroughly investigated. In this context, it is intriguing that serum concentrations of the cytokine tumor necrosis factor-alpha (TNF- $\alpha$ ) correlates with plasma C-peptide concentrations (Hotamisligil et al 1994; Hotamisligil 1999a, 1999b). TNF- $\alpha$ has been implicated as a causative key mediator of insulin resistance through direct interference with insulin signal transduction, TNF- $\alpha$ is an activator of NF- $\kappa \mathrm{B}$ (Yerneni et al 1999) and has been implicated in the pathogenesis of diabetic nephropathy (Moriwaki et al 2007). During the development of diabetic nephropathy, TNF- $\alpha$ has been shown to be expressed in renal glomeruli and proximal renal tubules (Nakamura et al 1993, Sugimoto et al 1999; DiPetrillo and Gesek 2004). Furthermore, disease progression is associated with increased serum concentrations of TNF- $\alpha$ and shows a positive correlation with urinary protein excretion (Hasegawa et al 1991; Kalantarina et al 2003). Additional studies have demonstrated that the administration of TNF- $\alpha$ impairs renal function (Schmidt et al 2007), and that inhibition of TNF- $\alpha$ decreases urinary albumin excretion in rats with experimental diabetes (Moriwaki et al 2007). Cumulatively, the evidence suggests a direct role for
TNF- $\alpha$ in the development of diabetic nephropathy, but the link to C-peptide remains controversial.

PI-3 kinase is necessary for cell proliferation and survival, and is involved in TNF- $\alpha$ signaling. The PI-3 pathway is implicated in the pathogenesis of diabetic endothelial dysfunction and atherosclerosis, and also this pathway has been shown to be increased by C-peptide (Brownlee 2001; Grunberger et al 2001; Kitamura et al 2001; Li et al 2003; Walcher et al 2006), implicating a synergistic effect of C-peptide and TNF- $\alpha$ in aggravating diabetes-associated complications. On the other hand, administration of C-peptide prevented TNF- $\alpha$-mediated apoptosis in opossum proximal tubular cells (Al-Rasheed et al 2006), suggesting a protective role of C-peptide in the progression of diabetes-related kidney disease. Hence, the interactions between TNF- $\alpha$ and C-peptide occur on multiple levels and outcomes may differ between different organs.

In addition to its causal role in vascular disease, NF- $\kappa \mathrm{B}$ is also essential for neuronal development and differentiation (Brand et al 1996; O'Neill and Kaitschmidt 1997; Denk et al 2000). In neurons, it may play a pro- or antiapoptotic role, depending on the cell type and the state of the cell (Brand et al 1996; O’Neill and Kaitschmidt 1997; Denk et al 2000). In the presence of insulin, C-peptide has been shown to exert antiapoptotic effects on neuroblastoma cells, and to increase the production of NF- $\kappa \mathrm{B}$ ( $\mathrm{Li}$ et al 2003). C-peptide has been suggested to be beneficial in diabetic neuropathy (Sima et al 2004) by promoting neuronal development, regeneration and cell survival. C-peptide prevents neuronal apoptosis in type 1 diabetes and in vitro, C-peptide induces neurite outgrowth and cell-growth of the neuroblastoma cell line SH-SY5Y (Li et al 2003; Li and Sima 2004).

To summarize, accumulating data suggest that C-peptide is involved in regulation of cell proliferation and apoptosis on multiple levels, mainly due to its association with inflammatory mediators, such as NF- $\kappa \mathrm{B}$ and TNF- $\alpha$. C-peptide appears to have predominantly antiproliferative effects in smooth muscle cells and beneficial roles in diabetic neuropathy, while renal effects of C-peptide remain controversial. C-peptide may, on the other hand, play a negative role in endothelial dysfunction due to activation of the PI-3 pathway.

\section{Immunoregulatory effects of C-peptide}

Nitric oxide synthase (NOS) and nitric oxide (NO) regulation are known to be altered in diabetic and inflammatory states (Scalia et al 2000; Langer et al 2002; Marx et al 2004). C-peptide increases eNOS and NO activity (Johansson 
et al 2003; Tsimaratos et al 2003; Walcher et al 2004; Maezawa et al 2006). In smooth muscle cells (Chakrabarti et al 2004) and aortic endothelial cells (Young et al 2000; Tsimaratos et al 2003), C-peptide has been shown to increase intracellular $\mathrm{Ca}^{2+}$, thereby inducing $\mathrm{NO}$ production by endothelial NOS (eNOS) and iNOS, causing an NO-dependent vasodilation. In myocardial ischemia-reperfusion, C-peptide has been shown to exert cardioprotective effects through the release of NO (Young et al 2000).

The impaired release of NO from the vascular bed will up-regulate adhesion molecules on endothelial cells, thereby increasing leukocyte-endothelium interactions (known as "rolling" and "sticking") (Scalia et al 2000). Early in the development of atherosclerosis, circulating monocytes adhere and migrate into the subendothelial space (Marx et al 2004). In isolated ischemic and reperfused rat hearts, C-peptide reduces polymorphonuclear cell adherence to vascular endothelium (Young et al 2000), and in an in vivo rat model of inflammatory vascular dysfunction, a single bolus injection of C-peptide decreased the expression of endothelial cell adhesion molecules on the rat microvascular endothelium, leading to reduced leukocyte rolling and adhesion as well as transmigration in mesenteric venules (Scalia et al 2000). This attenuation of leukocyte-endothelial interactions is mediated by an increase in eNOS synthesis and subsequent release of NO (Scalia et al 2000). Overall, these reports suggest that administration of C-peptide in physiological doses exerts antiinflammatory, and thus antiatherosclerotic effects.

Paradoxically, C-peptide has also been reported to possess proinflammatory properties. C-peptide improves dermal wound healing associated with an increased number of leukocytes adherent to the endothelium (Langer et al 2002). C-peptide has been reported to co-localize with macrophages and monocytes in artery specimens from diabetic subjects (Marx et al 2004), and to co-localize with and act as a chemoattractant for CD4-positive lymphocyte and monocytes in early atherosclerotic lesions (Walcher et al 2004). In Swiss 3 T3 fibroblasts, C-peptide (1 nM) has been shown to stimulate the transcription of inflammatory genes, such as cyclooxygenase-2 (COX-2), via the activation of a PKC/NF- $\mathrm{KB}$ signaling pathway (Kitazawa et al 2006). In view of these potential effects of C-peptide, it is important to determine whether the net effect of C-peptide supplementation is beneficial or detrimental for the development of diabetes-associated complications.

In summary, the role of C-peptide in the regulation of inflammation remains controversial, and further studies are needed in order to determine in which contexts treatment with
C-peptide would be beneficial from an immunomodulatory point of view.

\section{C-peptide-induced effects on angiogenesis}

It has been suggested that C-peptide has effects on angiogenesis (Chakrabarti et al 2004). There are indications that diabetes induces the up-regulation of oncofetal fibronectin in the retina (Khan et al 2004), a substance believed to be involved in angiogenesis and normally not found in mature tissue (Castellani et al 1994; Karelina and Eisen 1998). Increased retinal expression of oncofetal fibronectin in diabetic rats is completely prevented by C-peptide treatment (Chakrabarti et al 2004). This normalization of the diabetes-induced up-regulation of oncofetal fibronectin in diabetic retinas, may suggest an important role of C-peptide for the development of microangiopathy.

\section{Conclusion}

Given C-peptide's effects on NF- $\kappa \mathrm{B}$, TNF- $\alpha$, and PKC, plasma $\mathrm{C}$-peptide concentrations may play a pivotal role in the regulation of endothelial function. Thus, prescribed to the right patients, it is likely that C-peptide substitution would reduce the prevalence of diabetes complications. Accumulated evidence suggest that exogenous C-peptide possesses beneficial effects on diabetic complications in type 1 diabetic patients, and likely also in type 2 diabetic patients with relative $\mathrm{C}$-peptide deficiency. However, it may be that C-peptide does not prevent, but rather contributes to and promotes atherogenesis in patients with excess C-peptide production. It remains to be determined whether these seemingly divergent effects reflect tissue- or state-specific mechanisms.

So far, C-peptide studies have given several opportunities for new drug targets and research directions. Also, C-peptide-induced effects on NO production are not restricted to the diabetic state, but have been reported in models of ischemia-reperfusion as well as during inflammation. Concomitantly, the effectiveness of C-peptide in the prevention and reversal of diabetic complications merits further investigation, particularly in human subjects. Protection from diabetes-induced vascular dysfunction by C-peptide administration has been reported in small-scale clinical trials (Johansson et al 2000; Hansen et al 2002), but long-term, large-scale studies need to be conducted in order to determine safety and health outcomes of long-term administration of C-peptide to patients with diabetes. It is not unlikely that C-peptide substitution in physiological doses 
would improve endothelial dysfunction, prevent or induce the regression of the atherosclerotic lesions and reduce the risk of diabetes complications.

\section{Disclosure}

The authors report no conflicts of interest in this work.

\section{References}

Al-Rasheed NM, Willars GB, Brunskill NJ. 2006. C-peptide signals via Galpha i to protect against TNF-alpha-mediated apoptosis of opossum kidney proximal tubular cells. J Am Soc Nephrol, 17:986-95.

Brand K, Page S, Rogler G, et al. 1996. Activated transcription factor nuclear factor-kappa B is present in the atherosclerotic lesion. $J$ Clin Invest, 97:1715-22.

Brownlee M. 2001. Biochemistry and molecular cell biology of diabetic complications. Nature, 414:813-20.

Castellani P, Viale G, Dorcaratto A, et al. 1994. The fibronectin isoform containing the ED-B oncofetal domain: a marker of angiogenesis. Int $J$ Cancer, 59:612-8.

Chakrabarti S, Khan ZA, Cukiernik M, et al. 2004. C-peptide and retinal microangiopathy in diabetes. Exp Diabesity Res, 5:91-6.

[DCCT] The Diabetes Control and Complications Trial Research Group. 1993. The effect of intensive treatment of diabetes on the development and progression of long-term complications in insulin-dependent diabetes mellitus. The Diabetes Control and Complications Trial Research Group. N Engl J Med, 329:977-86.

Denk A, Wirth T, Baumann B. 2000. NF-kappaB transcription factors: critical regulators of hematopoiesis and neuronal survival. Cytokine Growth Factor Rev, 11:303-20.

De La Tour DD, Raccah D, Jannot MF, et al. 1998. Erythrocyte Na/K ATPase activity and diabetes: relationship with C-peptide level. Diabetologia, 41:1080-4.

DiPetrillo K, Gesek FA. 2004. Pentoxifylline ameliorates renal tumor necrosis factor expression, sodium retention, and renal hypertrophy in diabetic rats. Am J Nephrol, 24:352-9.

Fioretto P, Steffes MW, Sutherland DE, et al. 1998. Reversal of lesions of diabetic nephropathy after pancreas transplantation. $N$ Engl J Med, 339:69-75.

Fiorina P, Folli F, Zerbini G, et al. 2003. Islet transplantation is associated with improvement of renal function among uremic patients with type I diabetes mellitus and kidney transplants. J Am Soc Nephrol, $14: 2150-8$.

Forst T, Kunt T, Pohlmann T, et al. 1998a. Biological activity of C-peptide on the skin microcirculation in patients with insulin-dependent diabetes mellitus. J Clin Invest, 101:2036-41.

Forst T, Kunt T, Pfutzner A, et al. 1998b. New aspects on biological activity of C-peptide in IDDM patients. Exp Clin Endocrinol Diabetes, 106:270-6.

Grunberger G, Qiang X, Li Z, et al. 2001. Molecular basis for the insulinomimetic effects of C-peptide. Diabetologia, 44:1247-57.

Hansen A, Johansson BL, Wahren J, et al. 2002. C-peptide exerts beneficial effects on myocardial blood flow and function in patients with type 1 diabetes. Diabetes, 51:3077-82.

Hasegawa G, Nakano K, Sawada M, et al. 1991. Possible role of tumor necrosis factor and interleukin-1 in the development of diabetic nephropathy. Kidney Int, 40:1007-12.

Heliövaara MK, Teppo AM, Karonen SL, et al. 2005. Plasma IL-6 concentration is inversely related to insulin sensitivity, and acute-phase proteins associate with glucose and lipid metabolism in healthy subjects. Diabetes Obes Metab. 7:729-36.

Hotamisligil GS. 1999a. Mechanisms of TNF-alpha-induced insulin resistance. Exp Clin Endocrinol Diabetes, 107:119-25.

Hotamisligil GS. 1999b. The role of TNFalpha and TNF receptors in obesity and insulin resistance. $J$ Intern Med, 245:621-5.
Hotamisligil GS, Murray DL, Choy LN, et al. 1994. Tumor necrosis factor alpha inhibits signaling from the insulin receptor. Proc Natl Acad Sci $U S A, 91: 4854-8$.

Huang DY, Richter K, Breidenbach A. 2002. Human C-peptide acutely lowers glomerular hyperfiltration and proteinuria in diabetic rats: a dose-response study. Naunyn Schmiedebergs Arch Pharmacol, 365:67-73.

Ido Y, Vindigni A, Chang K, et al. 1997. Prevention of vascular and neural dysfunction in diabetic rats by C-peptide. Science, 277:563-6.

Jensen T, Bjerre-Knudsen J, Feldt-Rasmussen B, et al. 1989. Features of endothelial dysfunction in early diabetic nephropathy. Lancet, 1:461-3.

Johansson BL, Linde B, Wahren J. 1992. Effects of C-peptide on blood flow, capillary diffusion capacity and glucose utilization in the exercising forearm of type 1 (insulin-dependent) diabetic patients. Diabetologia, $35: 1151-8$.

Johansson BL, Borg K, Fernqvist-Forbes E. 2000. Beneficial effects of C-peptide on incipient nephropathy and neuropathy in patients with Type 1 diabetes mellitus. Diabet Med, 17:181-9.

Johansson BL, Wahren J, Pernow J. 2003. C-peptide increases forearm blood flow in patients with type 1 diabetes via a nitric oxide-dependent mechanism. Am J Physiol Endocrinol Metab, 285:E864-70.

Kalantarinia K, Awad AS, Siragy HM. 2003. Urinary and renal interstitial concentrations of TNF-alpha increase prior to the rise in albuminuria in diabetic rats. Kidney Int, 64:1208-13.

Karelina TV, Eisen AZ. 1998. Interstitial collagenase and the ED-B oncofetal domain of fibronectin are markers of angiogenesis in human skin tumors. Cancer Detect Prev, 22:438-44.

Khan ZA, Cukiernik M, Gonder JR, et al. 2004. Oncofetal fibronectin in diabetic retinopathy. Invest Ophthalmol Vis Sci, 45:287-95.

Kitamura T, Kimura K, Jung BD, et al. 2001. Proinsulin C-peptide rapidly stimulates mitogen-activated protein kinases in Swiss 3T3 fibroblasts: requirement of protein kinase $\mathrm{C}$, phosphoinositide 3-kinase and pertussis toxin-sensitive G-protein. Biochem J, 355:123-9.

Kitazawa M, Shibata Y, Hashimoto S, et al. 2006. Proinsulin C-peptide stimulates a $\mathrm{PKC} / \mathrm{IkappaB} / \mathrm{NF}-\mathrm{kappaB}$ signaling pathway to activate COX-2 gene transcription in Swiss 3 T3 fibroblasts. $J$ Biochem, 139:1083-8.

Kobayashi Y, Naruse K, Hamada Y, et al. 2005. Human proinsulin C-peptide prevents proliferation of rat aortic smooth muscle cells cultured in high-glucose conditions. Diabetologia, 48:2396-401.

Kunt T, Schneider S, Pfutzner A, et al. 1999. The effect of human proinsulin C-peptide on erythrocyte deformability in patients with Type I diabetes mellitus. Diabetologia, 42:465-71.

Langer S, Born F, Breidenbach A, et al. 2002. Effect of C-peptide on wound healing and microcirculation in diabetic mice. Eur J Med Res, 7:502-8.

Lee TC, Barshes NR, Agee EE. 2006. The effect of whole organ pancreas transplantation and PIT on diabetic complications. Curr Diab Rep, 6:323-7.

Li ZG, Zhang W, Sima AA. 2003. C-peptide enhances insulin-mediated cell growth and protection against high glucose-induced apoptosis in SH-SY5Y cells. Diabetes Metab Res Rev, 19:375-85.

Li ZG, Sima AA. 2004. C-peptide and central nervous system complications in diabetes. Exp Diabesity Res, 5:79-90.

Maezawa Y, Yokote K, Sonezaki K, et al. 2006. Influence of C-peptide on early glomerular changes in diabetic mice. Diabetes Metab Res Rev, 22:313-22.

Manzella D, Ragno E, Abbatecola AM, et al. 2003. Residual C-peptide secretion and endothelial function in patients with Type II diabetes. Clin Sci (Lond), 105:113-18.

Marx N, Walcher D, Raichle C, et al. 2004. C-peptide colocalizes with macrophages in early arteriosclerotic lesions of diabetic subjects and induces monocyte chemotaxis in vitro. Arterioscler Thromb Vasc Biol, 24:540-5. 
Moriwaki Y, Inokuchi T, Yamamoto A, et al. 2007. Effect of TNF-alpha inhibition on urinary albumin excretion in experimental diabetic rats. Acta Diabetol, 44:215-8.

Nakamura T, Fukui M, Ebihara I, et al. 1993. mRNA expression of growth factors in glomeruli from diabetic rats. Diabetes, 42:450-6.

Navarro JF, Mora C, Maca M, et al. 2003. Inflammatory parameters are independently associated with urinary albumin in type 2 diabetes mellitus. Am J Kidney Dis, 42:53-61.

Nordquist L, Moe E, Sjoquist M. 2007. The C-peptide fragment EVARQ reduces glomerular hyperfiltration in streptozotocin-induced diabetic rats. Diabetes Metab Res Rev, 23:400-5.

O’Neill LA, Kaltschmidt C. 1997. NF-kappa B: a crucial transcription factor for glial and neuronal cell function. Trends Neurosci, 20:252-8.

Pieper GM, Riaz-ul-Haq. 1997. Activation of nuclear factor-kappaB in cultured endothelial cells by increased glucose concentration: prevention by calphostin C. J Cardiovasc Pharmacol, 30:528-32.

Samnegard B, Jacobson SH, Jaremko G, et al. 2001. Effects of C-peptide on glomerular and renal size and renal function in diabetic rats. Kidney Int, 60:1258-65.

Samnegard B, Jacobson SH, Johansson BL, et al. 2004. C-peptide and captopril are equally effective in lowering glomerular hyperfiltration in diabetic rats. Nephrol Dial Transplant, 19:1385-91.

Sari R, Balci MK. 2005. Relationship between C peptide and chronic complications in type-2 diabetes mellitus. J Natl Med Assoc, 97:1113-8.

Scalia R, Coyle KM, Levine BJ, et al. 2000. C-peptide inhibits leukocyteendothelium interaction in the microcirculation during acute endothelial dysfunction. FASEB J, 14:2357-64.

Schmidt C, Hocherl K, Schweda F, et al. 2007. Regulation of renal sodium transporters during severe inflammation. J Am Soc Nephrol, 18:1072-83.

Shapiro AM, Ricordi C, Hering BJ, et al. 2006. International trial of the Edmonton protocol for islet transplantation. $N \mathrm{Engl} \mathrm{J} \mathrm{Med,}$ $355: 1318-30$

Sima AA, Zhang W, Grunberger G. 2004. Type 1 diabetic neuropathy and C-peptide. Exp Diabesity Res, 5:65-77.

Sjoquist M, Huang W, Johansson BL. 1998. Effects of C-peptide on renal function at the early stage of experimental diabetes. Kidney Int, 54:758-64.
Steffes MW, Sibley S, Jackson M, et al. 2003. Beta-cell function and the development of diabetes-related complications in the diabetes control and complications trial. Diabetes Care, 26:832-6.

Stridh S, Sällström J, Fridén M, et al. 2008. C-peptide normalizes glomerular filtration rate in hyperfiltrating streptozotocin-induced diabetic rats. In vivo measurements in conscious rats. Adv Exp Med Biol, In press.

Sugimoto H, Shikata K, Wada J, et al. 1999. Advanced glycation end products-cytokine-nitric oxide sequence pathway in the development of diabetic nephropathy: aminoguanidine ameliorates the overexpression of tumour necrosis factor-alpha and inducible nitric oxide synthase in diabetic rat glomeruli. Diabetologia, 42:878-86.

Tsimaratos M, Roger F, Chabardes D, et al. 2003. C-peptide stimulates $\mathrm{Na}+\mathrm{K}+$-ATPase activity via PKC alpha in rat medullary thick ascending limb. Diabetologia, 46:124-31.

Walcher D, Aleksic M, Jerg V, et al. 2004. C-peptide induces chemotaxis of human CD4-positive cells: involvement of pertussis toxin-sensitive G-proteins and phosphoinositide 3-kinase. Diabetes, 53:1664-70.

Walcher D, Babiak C, Poletek P, et al. 2006. C-Peptide induces vascular smooth muscle cell proliferation: involvement of SRC-kinase, phosphatidylinositol 3-kinase, and extracellular signal-regulated kinase 1/2. Circ Res, 99:1181-7.

Witztum JL, Steinberg D. 1991. Role of oxidized low density lipoprotein in atherogenesis. J Clin Invest, 88:1785-92.

Yerneni KK, Bai W, Khan BV, et al. 1999. Hyperglycemia-induced activation of nuclear transcription factor kappaB in vascular smooth muscle cells. Diabetes, 48:855-64.

Young LH, Ikeda Y, Scalia R, et al. 2000. C-peptide exerts cardioprotective effects in myocardial ischemia-reperfusion. Am J Physiol Heart Circ Physiol, 279:H1453-9.

Zhong Z, Davidescu A, Ehren I, et al. 2005. C-peptide stimulates ERK1/2 and JNK MAP kinases via activation of protein kinase $\mathrm{C}$ in human renal tubular cells. Diabetologia, 48:187-97.

Zhong Z, Kotova O, Davidescu A, et al. 2004. C-peptide stimulates Na+, $\mathrm{K}+-\mathrm{ATPase}$ via activation of ERK1/2 MAP kinases in human renal tubular cells. Cell Mol Life Sci, 61:2782-90. 